\title{
Entre Aldeia Kaingang ou Parque Natural: o processo de configuração de um conflito socioambiental na disputa pelo Morro do Osso, Porto Alegre, RS
}

\section{Between Kaingang Village or Natural Park: the Process of Configuration of a Socio-Environmental Conflict in Contention for Morro do Osso, Porto Alegre, RS}

\author{
Guilherme FUHR* \\ Cleyton Henrique GERHARDT ${ }^{* *}$ \\ Rumi Regina KUBO***
}

\begin{abstract}
RESUMO
O presente artigo tem como foco os conflitos socioambientais em torno das lógicas de ocupação do Morro do Osso - Porto Alegre, Brasil. As disputas envolvendo tipos diferenciados de apropriação, uso e significação dessa área têm motivado a atuação de instituições, organizações e agentes sociais bastante heterogêneos. A partir do final da década de 1970, ambientalistas preocupados com o avanço da urbanização se articularam com vistas a garantir a preservação do Morro, processo que culminou com a criação do Parque Natural Morro do Osso. Dez anos mais tarde, em 2004, indígenas Kaingang passaram a reivindicar a demarcação de uma Terra Indígena no Morro do Osso em área que se sobrepõe ao Parque. Assim, duas territorialidades emergiram e passaram a polarizar os conflitos: de um lado, os que defendem a manutenção da institucionalização do Parque Natural Morro do Osso, e, de outro, esforços pelo reconhecimento e demarcação da Aldeia Kaingang Topë pën. Portanto, são justamente as tensões e implicações resultantes dessa polarização que trataremos aqui, de modo a trazer à tona parte dos embates discursivos e os desdobramentos desta disputa territorial que, até o presente momento, como veremos, vem se demonstrando adialógica e sem perspectivas de conciliação entre as partes envolvidas no litígio, seguindo uma lógica de "perdedores e vencedores" para o desfecho da disputa.
\end{abstract}

Palavras-chave: conflitos socioambientais; Kaingang; Parque Natural Morro do Osso.

\footnotetext{
"Biólogo, mestrando em Desenvolvimento Rural pelo Programa de Pós-Graduação em Desenvolvimento Rural da Universidade Federal do Rio Grande do Sul. E-mail: biofuhr@yahoo.com.br

** Doutor em Ciências Sociais Aplicadas ao Mundo Rural (UFRJ). Professor adjunto da Universidade Federal do Rio Grande do Sul (UFRGS) e pesquisador permanente do Programa de Pós-Graduação em Desenvolvimento Rural (PGDR/UFRGS). E-mail: cleytonge@gmail.com

*** Doutora em Antropologia Social (UFRGS). Professora do Departamento de Ciências Econômicas da Universidade Federal do Rio Grande do Sul (UFRGS). E-mail: rumikubo2002@yahoo.com.br
} 


\begin{abstract}
This article describes the socio-environmental conflicts around the logics of occupation at Morro do Osso (Bone's Hill) in Porto Alegre, Brazil. Disputes involving different types of appropriation, use and significance of this area have been motivating actions of quite heterogeneous institutions and social organizations. Since the late 70's, environmentalists who were concerned about the growing urbanization mobilized to ensure the hill's preservation, a process that culminated on the creation of Morro do Osso Natural Park. Ten years later, in 2004, Kaingang indigenous people began to claim the demarcation of an indigenous land at Morro do Osso on an area that overlaps the Park. Thus, two territorialities emerged and began to polarize the conflict: on the one hand, those who favor maintaining the Morro do Osso Natural Park institutionalization; on the other hand, efforts for the Topë pën Kaingang's land recognition and demarcation. Therefore, precisely the resulting tensions and implications of this polarization will be discussed here in order to bring out part of the discursive arena and the consequences of this territorial dispute, that, to date, has been demonstrating nothing dialogical and no prospect of consensus agreement between the parties involved, following a logic of "winners and losers" to the outcome of the dispute.
\end{abstract}

Keywords: socio-environmental conflicts; Kaingang indians; Morro do Osso Natural Park.

\section{Introdução}

O presente trabalho traz à luz o debate referente aos conflitos socioambientais desencadeados em torno das lógicas de ocupação/territorialização de uma área de cerca de 220 hectares (ha) do município de Porto Alegre conhecida por Morro do Osso. As disputas envolvendo tipos diferenciados de apropriação, uso e significação desta área têm sido recorrentes, sobretudo nas últimas três décadas. Ao mesmo tempo, têm motivado a atuação de instituições, organizações e agentes sociais bastante heterogêneos.

A partir do final da década de 1970, ambientalistas preocupados com o avanço do processo de urbanização e da especulação imobiliária e consequente degradação ambiental do Morro do Osso, se articularam com vistas a garantir sua preservação, processo este que culminou com a criação, em 1994, do Parque Natural Morro do Osso (PNMO). ${ }^{1}$ Dez anos mais tarde, em 2004, indígenas da etnia Kaingang passaram a reivindicar a demarcação de uma Terra Indígena (TI) no Morro do Osso em área que abrange e sobrepõe-se ao PNMO. A partir desta demanda Kaingang relacionada à sua histórica luta pela terra, duas territorialidades emergiram e passaram a polarizar os conflitos decorrentes: de um lado, não indígenas que defendem a manutenção e garantia da integridade do Parque Natural Morro do Osso e, de outro, indígenas e seus aliados lutando pelo reconhecimento, regularização e demarcação da Aldeia Topë pën. ${ }^{2}$

Neste texto, procurar-se-á trazer os diferentes momentos e atores sociais que se envolveram nesse processo de configuração desta polarização, que apresentam contornos diversificados, bem como as tensões e implicações resultantes desta situação antagônica, de modo a trazer à tona parte dos embates discursivos e dos desdobramentos concretos que puderam ser visualizados e percebidos até o presente momento.

Quanto à organização do artigo, primeiramente, o texto traz uma breve descrição da área de estudo (Morro do Osso), com ênfase na importância em termos ambientais e nos aspectos relativos à sua biodiversidade; em seguida, apresentamos alguns aspectos ligados aos Kaingang enfocando a dinâmica que caracteriza sua

\footnotetext{
${ }^{1}$ O Parque Natural Morro do Osso é uma Unidade de Conservação (UC). Atualmente, Porto Alegre possui três Unidades de Conservação administradas municipalmente: a Reserva Biológica do Lami - José Lutzenberger, o Parque Natural Saint'Hilaire e o Parque Natural Morro do Osso (PNMO); além do Parque Estadual Delta do Jacuí, administrado estadualmente.

${ }^{2}$ Aldeia Pé-de-Deus (Tupë = Deus e pën= pé). As expressões Kaingang virão em itálico. A grafia do idioma Kaingang adotada foi a do Dicionário Bilíngue Kaingang - Português de Wiesemann (2002). Grafaram-se com trema as vogais "i", "e", "u" e "y" do idioma Kaingang, quando o correto seria fazê-lo com til, o que o editor de textos utilizado não permitiu fazê-lo.
} 
presença em centros urbanos como Porto Alegre e os vínculos que os unem, assim como seus vínculos a outras Terras Indígenas no interior do Estado; já num terceiro momento, enfoca-se especificamente a questão da espacialização dos conflitos socioambientais no Morro do Osso, culminando com a implementação e funcionamento do Parque Natural Morro do Osso; por fim, partimos para a descrição das situações conflituosas e tensas geradas com a ocupação Kaingang em parte da área do Parque, procurando com isso analisar alguns desdobramentos e implicações relativos à sobreposição hoje existente entre essas duas territorialidades distintas: o PNMO já instituído chocando-se com a demanda Kaingang pela área, a partir da, também já constituída, Aldeia Topë pën do Morro do Osso. Por fim, serão tecidas algumas considerações finais sobre o referido estudo de caso.

\section{O território Morro do Osso: espacialidade ambiental e biodiversidade cientificada}

Ao contrário da maioria dos conflitos ambientais deflagrados entre etnias indígenas e não indígenas, cujas disputas envolvem a apropriação e uso de territórios relativamente menos urbanizados, a área do presente estudo, reivindicada pelos Kaingang, acha-se localizada no coração de uma cidade com quase um milhão e meio de habitantes (Porto Alegre). Cercado pela malha viária de duas avenidas de grande circulação (Cavalhada e Coronel Marcos), em volta do Morro do Osso acham-se os bairros Cavalhada, Camaquã, Tristeza, Vila Conceição, Pedra Redonda e Ipanema.

Por outro lado, o Morro do Osso é um dos 44 morros graníticos do município de Porto Alegre, sendo o único que abriga uma Unidade de Conservação (UC), estando localizado na zona sul da cidade, próximo à margem do Lago Guaíba, elevando-se entre os morros da Ponta dos Cachimbos e da Ponta da Pedra Redonda (Morro do Sabiá). De acordo com o Diagnóstico Ambiental de Porto Alegre:

\begin{abstract}
O Morro do Osso, que atinge $143 \mathrm{~m}$ de altura, apresenta vegetação com matas e campos rupestres - com matacões de granito e solos jovens, rasos e rochosos. Sua formação é de Granito Ponta Grossa, com solos litólicos e neossolos. Apesar da sua importância ambiental, encontra-se altamente ameaçado por ocupações irregulares e isolado pela urbanização dos bairros do seu entorno (HASENACK et al., 2008, p. 79).
\end{abstract}

Ao observarmos o mapa de Porto Alegre, vemos que a área em questão situa-se no extremo oeste da "Crista de Porto Alegre", uma cadeia de morros com aproximados $22 \mathrm{~km}$ de comprimento, situada na região central do município, estendendo-se de sudoeste (Morro do Osso) a nordeste (Morro Santana). ${ }^{3}$ Essa formação geológica, até o final do século passado, serviu como limitador da expansão urbana no sentido meridional formatando uma barreira - apresentando ao norte um cenário cinza e urbanizado e ao sul, verde, característico do meio rural (MENEGAT, 1999).

O Morro do Osso ainda possui em torno de 210 ha de áreas verdes, dos quais 127 ha concernem ao Parque Natural Morro do Osso. Constitui-se num refúgio para diferentes espécies vegetais e animais. Genericamente, sua vegetação é composta por $60 \%$ de formações florestais e $40 \%$ de campos e "vassourais". Como em outros morros de Porto Alegre, os campos ocupam porções das encostas norte e de topos de morros; já as matas ocupam as encostas voltadas ao sul, os vales e as baixadas. ${ }^{4}$

\footnotetext{
${ }^{3}$ A Crista de Porto Alegre é constituída pelos morros do Osso, Teresópolis, da Glória, da Pedra Redonda, da Polícia, Pelado, da Companhia e morro Santana. Este último é o ponto mais alto de Porto Alegre $(311 \mathrm{~m})$ e tem área aproximada de mil ha, dos quais 600 ha pertencem à Universidade Federal do Rio Grande do Sul (UFRGS). O Morro Santana possui semelhanças com o caso do Morro do Osso, sendo também um território em disputa entre os Kaingang e os não índios. Além de também constituir um importante ponto na constituição da territorialidade Kaingang, suas matas acham-se também ameaçadas pela especulação imobiliária e expansão urbana. Contudo, as situações se diferenciam pelo fato de, no caso do Morro Santana, ainda não haver uma UC formalmente constituída, sendo sua criação uma demanda pleiteada por entidades ambientalistas, órgãos municipais e a própria UFRGS. Ressalta-se ainda que os Kaingang já possuem direito legal de circular e manejar as florestas e campos deste território, segundo Agravo de Instrumento N ${ }^{\circ}$ 7807-73.2010.404.0000/RS (Boletim Jurídico n 115 da Escola da Magistratura do TRF da $4^{\text {a }}$ Região, 2011).

${ }^{4}$ Brack et al. (1998) constataram que no Morro do Osso podem ser encontradas sete das onze formações vegetais presentes no município: mata higrófila, mata mesófila, mata subxerófila, vegetação arbóreo-arbustiva de campos pedregosos, capoeiras, vassourais e os campos pedregosos.
} 
Em relação à biodiversidade do Morro do Osso, segundo o Plano de Manejo do PNMO, que divulga o inventariamento de espécies organizado por Mirapalhete (2001), há 28 plantas que constam na Lista de Espécies da Flora Ameaçadas do Rio Grande do Sul com algum grau de ameaça de extinção (Decreto Estadual n ${ }^{\circ}$ 42.099/03). ${ }^{5}$ Além disso, foram encontradas 140 espécies de árvores, contemplando $80 \%$ das 171 espécies arbóreas que ocorrem em Porto Alegre. Já com relação aos inventários de fauna, foram encontradas 137 espécies de vertebrados, sendo 5 de mamíferos: gambá-de-orelha-branca (Didelphis albiventris), morcego-das-casas (Sturnira lilium), preá (Cavia aparea), ouriço-cacheiro (Sphiggurus villosus) e um indivíduo de bugio-ruivo (Alouatta guariba clamitans); também foram registradas 12 espécies de anfíbios ( 5 de rãs, 4 de pererecas e 3 de sapos); 10 espécies de répteis (6 de cobras, 3 de lagartixas e uma de lagarto); e foram avistadas 110 espécies de aves - o que corresponde a $65 \%$ da avifauna com registro para o município de Porto Alegre (MIRAPALHETE, 2001). Cabe também comunicar que não foi encontrada nenhuma espécie endêmica, isto é, de ocorrência restrita ao Morro do Osso.

Em síntese, embora hoje em dia "ilhado" por avenidas, casas, comércio, carros, indústrias, poluição e outros elementos da urbanidade contemporânea, o Morro do Osso continua sendo, do ponto de vista biológico, um fragmento (em mosaico de vegetações) relativamente preservado. Esse e outros atributos são, sob diferentes modos, acionados por parte dos atores envolvidos no conflito em análise.

A diversidade biológica existente, a paisagem, seu caráter pedagógico, aliados ao fato de o morro proporcionar um ambiente de lazer aos moradores da cidade, o perigo constante de a área sofrer ocupações irregulares e o avanço da especulação imobiliária, por exemplo, poderão ser acionados como argumentos que visem, em determinadas situações, fixar pontos de vista sobre o que está em jogo no conflito, isto é, o modo como o que se conhece por Morro do Osso deveria (e deve) ser apropriado, utilizado e significado.

\section{Territorialidades Kaingang em Porto Alegre}

Historicamente, os Kaingang ocuparam áreas de florestas com pinheiros (floresta ombrófila mista - mata com araucárias) e de campos do planalto sul-brasileiro. Portanto, ao longo dos últimos quatro séculos, viveram as diversas modificações que levaram ao desaparecimento e á degradação de grande parte dos elementos naturais que compunham seu território. Já no início do contato e interação com os conquistadores brancos, os Kaingang tiveram que enfrentar a implementação de um sistema extrativista altamente devastador. A visão imediatista colonial visava simplesmente extrair ao máximo os recursos naturais existentes, sendo o principal deles a araucária ou pinheiro-brasileiro (Araucaria angustifolia), que era justamente a principal fonte de alimento para o povo Kaingang (SCHMITZ, 2009).

Mas, com a chegada da "ideologia do desenvolvimento", outras "extrações" foram sendo impostas aos Kaingang. À perda de seu território, ao aldeamento forçado, à expansão das fazendas de criação de gado, à intensificação da grilagem e arrendamento de terras-vieram se somar o avanço da fronteira agrícola, a expropriação causada pela construção de barragens, estradas, ferrovias e projetos de mineração, a exclusão via expansão desordenada e caótica das cidades e, finalmente, a desterritorialização causada pela criação e implementação de Unidades de Conservação.

Ainda assim, o povo Kaingang constitui hoje a maior população indígena do sul do Brasil e uma das maiores do país, sendo diversas comunidades Kaingang encontradas nos Estados do Rio Grande do Sul, Santa Catarina, Paraná e São Paulo (SILVA, 2002), além de ocuparem áreas na província de Misiones, Argentina (FREITAS, 2005). Segundo dados oficiais da Fundação Nacional de Saúde (FUNASA) ${ }^{6}$ a população Kaingang no Brasil é de 33.876 pessoas, sendo que, no Rio Grande do Sul, são 17.515 indivíduos, ou seja, 52\% do povo Kaingang vive neste Estado. Porém, a despeito de serem

\footnotetext{
${ }^{5}$ Das 28 espécies, 21 delas encontram-se na categoria "Vulnerável" e 7 na categoria "Em perigo".

${ }^{6}$ A FUNASA foi responsável pela Atenção Integral à Saúde Indígena até 2010, quando criou-se a Secretaria Especial de Saúde Indígena (SESAI), a qual assume essa incumbência a partir de então. Os dados apresentados acima são referentes ao relatório demográfico da FUNASA do ano de 2010 e podem ser consultados em: $<$ http://sis.funasa.gov.br/transparencia_publica/siasiweb/Layout/quantitativo_de_pessoas_2010.asp>.
} 
informações recentes, os números apontados possuem aplicação limitada, tendo em vista a dinâmica social particular que caracteriza a cultura e a organização social Kaingang. O que importa, neste caso, é constatar, mais do que o aspecto demográfico Kaingang, a dinâmica de configuração do universo sociocosmológico daqueles. À histórica presença Kaingang em centros urbanos soma-se a sua relativa mobilidade espacial e temporal, resultando na estruturação e reelaboração de complexas e diversificadas redes sociais baseadas no parentesco e em mecanismos de reciprocidade e faccionalidade, de modo a articular diferentes territórios/territorialidades Kaingang. Tais articulações permitem conectar tanto áreas já reconhecidas como Terras Indígenas como vinculá-las a outras possíveis áreas a serem assim demarcadas.

E aqui realçamos o que propõe Freitas (2005, p. 20), quando alerta para o fato de que a região de "Porto Alegre é percebida pelos Kaingang como uma zona de profunda significação no contexto de seu território tradicional, na medida em que conecta as florestas do Planalto com as terras baixas do litoral, limite do mundo". Além disso, essas mesmas significações não se restringem a sua dimensão espacial (no caso, florestas do Planalto e o litoral "limite do mundo"), visto que implicam relações envolvendo todo um passado vivido, também, no que hoje chamamos Porto Alegre. Também Freitas (2008, p. 5) argumenta sobre o território do que hoje chamamos de Porto Alegre: "sabe-se que nela se situam territórios de pertencimento de distintos povos indígenas há pelo menos 9.000 anos antes do presente". Do mesmo modo, Silva et al. (2008, p. 123-124) comentam que:

Os deslocamentos kaingang para a Bacia do Lago Guaíba parecem ser muito recuados no tempo. Aldeias atuais localizadas nas regiões hidrográficas Taquari-Antas, Caí e Sinos (como, por exemplo, as aldeias de Estrela e de São Leopoldo) indicam este desbordar desde o Planalto de populações kaingang rumo ao sul e ao litoral. No passado pré-histórico, muitos assentamentos dos seus antepassados estão presentes nas regiões citadas. Muitos documentos históricos do final do século XIX e início do século XX atestam sua presença inegável na Bacia do Lago Guaíba, quando suas relações constantes e duradouras com os presidentes da Província e outras autoridades que os recebiam para tratar de seus interesses, além de outros motivos ligados à tradição, faziam-nos empreender longas expedições a pé por este território deles tão conhecido.

Aquino (2009b, p. 113) aponta que, a partir do final dos anos 1980, os "acampamentos e aldeias foram constituídos por pessoas que, em sua maioria, vieram da aldeia de Nonoai e, em menor número, da aldeia de Guarita, Votoro e de outras aldeias no planalto, localizadas no Noroeste do Rio Grande do Sul”. Portanto, será dentro deste contexto dinâmico envolvendo constantes permanências e deslocamentos, bem como da organização em coletivos diversos (comunidades, redes de parentesco, famílias extensas e nucleares), que o povo Kaingang se insere (mas, também, é excluído/invisibilizado) historicamente no processo de constituição do que hoje chamamos Porto Alegre. Esse processo relaciona-se com um fenômeno que se intensificou a partir de 1988, com a aprovação da Constituição Federal, que se, por um lado, legitimou e garantiu o direito indígena à diferença cultural e à livre circulação, por outro trouxe o desafio de construir condições para a efetivação desse preceito no âmbito das políticas públicas.

Atualmente, o poder público municipal reconhece o direito dos indígenas demarcarem suas terras no perímetro da cidade de Porto Alegre. No caso fundiário específico Kaingang, dentro da jurisdição do município já estão amparadas legalmente (Lei n ${ }^{\circ} 6.001$, de 1973) duas áreas: a aldeia de sete hectares da Lomba do Pinheiro e a aldeia de menos de um hectare da Agronomia. A essas se somam áreas domiciliares não reconhecidas pelo poder estatal, como a aldeia do Morro do Osso, os domínios do Morro Santana (caracterizados por núcleos familiares extensos residentes das vilas Jarí, Safira e Jardim Protásio Alves) e um núcleo familiar recentemente estabelecido no Morro da Glória.

De fato, a despeito da luta tanto dos Guarani e Charruas como dos Kaingang pela garantia de seus direitos originários e constitucionais, a institucionalização e o reconhecimento de sua presença na capital do Estado pelo poder público (nas esferas federal, estadual e municipal) têm se efetivado de modo débil, incerto e ocasional. Como afirma Freitas (2008, p. 6), referindo-se principalmente aos últimos vinte anos, esse "movimento de existência indígena em Porto Alegre tem produzido importantes mudanças no município, em suas estruturas 
e rotinas administrativas, embora ainda esteja distante da efetivação dos direitos consuetudinários destes povos na esfera local".

Tanto através dos diversos momentos em que se teve contato e interlocução com os Kaingang como a partir da bibliografia especializada referente a sua cosmologia (AQUINO, 2008; FREITAS, 2005, 2006; SALDANHA, 2009; SILVA, 2001, 2002, 2005, 2008; ROSA, 2005, dentre outras), podemos constatar a existência de uma intrínseca relação entre a cultura Kaingang e o que denominamos "natureza", como no caso do mato. É desse que provêm, por exemplo, os nomes indígenas dados às crianças pelo Kujà (liderança espiritual Kaingang que, no universo dos brancos, é mais conhecida pelas expressões xamã e pajé) através de seu Iangrë, uma entidade que guia e confere poder ao Kujà; da mesma forma, além da figura do Iangrë ser geralmente representada por um animal selvagem do mato, visto não poder ser associado a um bicho manso (SILVA, 2005), é a partir de elementos do matão que se obtêm a cura, os alimentos, as tintas para as pinturas corporais empregadas em eventos cerimoniais e as matérias-primas (como cipós e taquaras) usadas para confeccionar seus artesanatos e utensílios diversos utilizados no dia a dia das aldeias.

De fato, essa relação indissociável entre mato, entidades concretas, simbólicas e míticas e práticas culturais próprias da vida cotidiana Kaingang os leva a deter um profundo saber, tanto acerca dos diversos usos do que se costuma denominar "recursos naturais" bem como sobre os locais (caminhos, parques, praças, ruas, bairros, beira de estradas etc.) onde estes "recursos" podem ser encontrados e o modo como devem ser manejados. Segundo Souza-Pradella (2008),

os Kaingang possuem ampla mobilidade por esta cidade [Porto Alegre] e, consequentemente, um vasto conhecimento com relação aos espaços verdes e caminhos para alcançá-los dentro da cidade, já que sua existência material nesse contexto depende da relação com a mata, da coleta de fibras vegetais - cipós e taquara -, materiais com os quais confeccionam cestos e outros artesanatos. (p. 2).

Mas, para além da simples coleta e fabricação de artesanato, o manejo do mato executado pelos Kaingang nos fragmentos florestais de Porto Alegre acha-se vinculado à existência de um complexo sistema animista, envolvendo extrativismos, plantios, cultivos, podas, rotatividade das áreas manejadas e observações de mecanismos regeneradores, como o rebrote de cipós e taquaras. Conforme escreve Freitas (2006), ao narrar um diálogo que teve com Zílio Jagtyg:

As manchas [de cipó] são entendidas como o território de uma matriz ( $k a$ nèr ), tronco que expande seus ramos (fèj) pelo solo da floresta em busca de um apoio para trepar (tãpry). [...] Jagtyg associa a matriz ao pai (panh) de uma família, sendo os ramos compreendidos como seus filhos (kòsin): "uma mancha de cipó é assim como uma família; o tronco velho deles é o mais velho, é como o pai deles todos. Os mais novinhos é que correm em volta do pai e vão fazendo a vida deles." Quando perguntei a Zílio o que seria a comunidade, me respondeu: "a comunidade são os tipos todos que existem numa mancha, todos os pais de família, eles é que formam a comunidade, a aldeia deles; o gòjé (mancha) é a aldeia deles" (p. 228-229).

Segundo a mesma autora, referenciando-se à tradição do Kaingang-pé - conjunto de práticas e modos de ser, vinculados às cosmovisões dos antepassados (troncos velhos) -, os Kaingang vivem, praticam e reinventam o Mrû'r Jykre, expressão traduzida pela autora como "a cultura do Cipó" (FREITAS, 2005). Freitas refere, ainda que, "o manejo Kaingang do cipó preserva a matriz/pai (panh), que jamais é cortada", sendo dois os motivos apontados: "a matriz deve ser mantida para novamente fornecer cipó - ramos/filhos (kòsin), e que a matriz não tem utilidade para o artesanato por ser muito espessa e sem elasticidade" (FREITAS, 2006, p. 229).

$\mathrm{O}$ mato não se restringe apenas a um caráter utilitário, como, por exemplo, dar nome a elementos da vida Kaingang ou, então, como fonte de matérias-primas para produção de artesanato. Mais do que isso, a própria existência dos Kaingang, seu modo de estar no mundo, bem como os sentidos por eles imputados a este mesmo mundo acham-se intimamente associados aos ciclos reprodutivos e à dinâmica viva do mato. A noção do Mrû'r Jykre diz respeito a um conjunto de concepções, práticas e relações ecológicas, cosmológi- 
cas, sociopolíticas e econômicas centradas no manejo de trepadeiras lenhosas (cipós) que vicejam nas florestas do sul do Brasil. Esse conjunto de relações, por sua vez, sustenta-se nas interfaces entre as redes de reciprocidade Kaingang (que se territorializam de diferentes modos) e os espaços intersocietários da sociedade envolvente, incluindo aí o ambiente das cidades. Em Porto Alegre, o Mrû'r Jykre se materializa a partir da observação, extração e posterior transformação de partes de inúmeras espécies de plantas em cestos, balaios, vasos, ornamentos e outros objetos que acabam ingressando em circuitos de comércio e escambo, sobretudo, mas não só, nas diversas feiras locais existentes no município (FREITAS, 2005).

Ao serem ressignificados como artesanato, tanto aqueles utensílios que originalmente possuíam um valor de uso direto para os Kaingang como aqueles que, com o passar do tempo, foram sendo confeccionados especificamente para "venda", passaram a ter, também, algum tipo de valor de troca. Porém, as relações constituídas através desta relação mercantil integram uma base social e territorial bem mais ampla, a qual se acha definida pelo conjunto de espaços ocupados através da coleta, manejo, fabricação e comercialização de diferentes tipos de artefatos. Mesmo que descontínuos, esporádicos e fragmentados no mosaico da paisagem municipal, os locais onde se dá a efetivação desse valor (ou seja, a troca em si) são sistematicamente interligados pelo fluxo ecossocial indígena (FREITAS, 2005). Articulados através de suas redes de parentesco, do contato com a sociedade envolvente, da relação imaterial com os seres que povoam o matão, do intercâmbio de plantas, materiais, práticas, conhecimentos e técnicas em um devir por entre feiras, calçadas, ruas, praças, parques, beira de estradas, rodoviárias, aldeias, acampamentos, eventos diversos e demais espaços de troca constituem não só lugares de sociabilidade e de articulações diversas entre os próprios Kaingang, mas também entre estes e os fóg (os não indígenas) e com outras etnias indígenas.

De fato, em Porto Alegre e municípios próximos, aldeias, acampamentos e áreas de mato se interconectam com outros territórios, sendo os pontos de comercialização de seus artesanatos responsáveis, atualmente, pela principal fonte de renda para as comunidades Kaingang das aldeias e acampamentos na grande Porto Alegre. Além desses pontos de troca/venda se constituírem em lugares de encontro semanal entre Kaingang, entre estes e outras etnias indígenas e não indígenas, possibilitando um contato intra e interétnico, eles permitem e subentendem trocas de diversas ordens, sejam elas simbólicas, linguísticas, afetivas, monetárias, de experiências, de técnicas e informações ou mesmo de materiais usados na fabricação de peças artesanais. Por outro lado, sendo áreas de fácil acesso e uso comum (pois se tratam de praças e vias públicas), garantem maior visibilidade social, na medida em que serão, sobretudo a partir deles, que os Kaingang irão aparecer para a sociedade envolvente, além de possibilitar momentos de interação com índios Charrua e Guarani - outras etnias com presença na capital. Com efeito, além de dar visibilidade aos seus corpos, à sua fala, ao seu modo de ser no mundo e, no limite, à sua própria cultura, ${ }^{7}$ constituem ambientes de diálogo em que a língua Kaingang se mescla e se soma ao português e ao guarani. Ou seja, não se trata apenas de pontos de comércio e trocas monetárias, visto que, além da dimensão econômica, constituem também territórios políticos, de articulação identitária, de afirmação da alteridade e de intenso intercâmbio intra e interétnico.

\section{A disputa pelo "morro" e o processo de institucionalização do PNMO}

Uma das explicações dadas para o nome Morro do Osso vem de uma citação de Antônio do Vale Caldre e Fião em sua obra "Ibuicui-Retã", de 1875, publicada no Boletim Municipal em 1943 por Walter Spalding (SESTREN-BASTOS, 2006).

A fabricação de vasos era adiantada e quase perfeita, e prova disso temos no cemitério deles, no morro dos

\footnotetext{
${ }^{7}$ Sobre a noção de cultura, não entraremos no debate acerca do caráter generalizante, homogeneizador e utilitarista por vezes a ela imputado, tampouco abordaremos as recentes proposições de Cunha (2009, p. 373) acerca da distinção entre cultura entendida como "rede invisível na qual estamos suspensos" e "cultura" como "metadiscurso reflexivo sobre a cultura [...], recurso ou arma para firmar identidade, dignidade e poder diante de Estados nacionais ou da comunidade internacional". Contudo, em outro momento, tais aspectos deverão ser trabalhados e problematizados a partir do universo empírico estudado.
} 
FUHR, G.; GERHARDT, C. H.; KUBO, R. R. Entre Aldeia Kaingang ou Parque Natural: o processo de configuração...

ossos próximo desta cidade, além de Santa Tereza, onde se achavam, ainda há bem pouco tempo, grandes panelas contendo cadáveres secos ou ossos dos homens (tapís) de tempos remotos. (CALDRE E FIÃO, 1943, p. 419-420).

Essa informação está no plano de manejo do PNMO, assim como:

[...] a própria Prefeitura de Porto Alegre em seu website na Internet divulgava a existência de um sítio arqueológico de um cemitério indígena no Morro do Osso no tópico sobre informações turísticas. Tais informações eram decorrentes do fato do próprio morro ter recebido seu nome devido a relatos de que era comum nos séculos XVIII e XIX serem encontrados ossos indígenas naquela região [...] (SOUZA-PRADELLA; SALDANHA, 2008, p. 59).

Outra explicação para o nome do morro, que também consta no plano de manejo do PNMO, é de que o local era palco do tradicional jogo do osso, sendo o seu platô uma antiga cancha, devido a sua vista privilegiada para observação de possíveis batidas policiais, visto que o jogo envolvendo apostas era/é ilegal (SESTREN-BASTOS, 2006). Nas próprias palavras do projeto de Lei Municipal (aprovada em 1998) ${ }^{8}$ que nomeia o parque, afirma que, além da presença do cemitério indígena: "O Morro do Osso também abrigou Quilombos de escravos que fugiram da então cercada Porto Alegre. O local também servia de esconderijo para os fugitivos do presídio localizado na Ilha das Pedras Brancas, próxima ao Morro."

Por fim, ainda sobre as distintas versões sobre o nome do morro, cabe problematizar as diferentes explicações para a origem da nomeação deste território [Morro do Osso] - como parte do próprio conflito -, ou seja, as diversas explicações para a titulação do morro são afirmações que partem de pontos de vista específicos e, portanto, representam a própria disputa em jogo.

Ao longo da história de exploração e ocupação do Morro do Osso, podemos evidenciar diferentes práticas de uso do espaço e dos recursos nele disponíveis. Em diversas partes do morro, principalmente encostas e cumes, houve extração de granito (do tipo Ponta Grossa), ou seja, atuação de pedreiras, que até a década de 1980 dinamitavam gigantescos blocos de granito para posterior beneficiamento, transporte e comercialização das rochas; para tanto, as pedreiras abriam picadas e praticavam queimadas a fim de tornar essa atividade extrativista viável. Conforme salienta o Diagnóstico Ambiental de Porto Alegre, os próprios prédios do Memorial do Rio Grande do Sul, Santander Cultural (antigo Banco Nacional do Comércio), Museu Júlio de Castilhos e a Catedral Metropolitana de Porto Alegre foram construídos com Granito Ponta Grossa (HASENACK et al., 2008). Também tiveram seu ciclo no morro outras atividades, tais como a retirada mecanizada de terra preta ${ }^{9}$ do sub-bosque das matas e plantio/silvicultura de acácia-negra (Acacia decurrens), esta última atividade praticada principalmente na face norte e no topo do morro. Ressaltamos que a acácia-negra é uma espécie exótica da América (sendo originária do sul da Austrália e Tasmânia) e também considerada invasora, devido a sua fácil dispersão, sendo atualmente encarada como um grande problema ambiental na paisagem do morro (SESTREN-BASTOS, 2006), visto que ela está se espraiando rapidamente pelos vassourais e campos nativos do Morro do Osso.

Podemos considerar que os conflitos socioambientais emergiram com intensidade e maior visibilidade no Morro do Osso a partir de meados da década de setenta, no momento em que se inicia o envolvimento de diversos atores sociais contrários aos rumos exploratórios que vinham sendo exercidos no morro, assim estabelecendo, de forma genérica, uma arena política - um campo de forças polarizado -, uma disputa entre duas visões antagônicas: aspirações ambientalistas (preservacionistas) opondo-se ao que poderíamos chamar de uma ambição capital de exploração dos recursos naturais e pretensões urbanísticas. Ou seja, de um lado, alguns moradores da região e agentes intitulados ambientalistas e ecologistas

${ }^{8}$ Lei Municipal n 8.155, de 12/5/1998 - que denomina Parque Natural Morro do Osso a Área Funcional do Parque Natural, criada pela Lei Complementar 334, de 27/12/1994.

${ }^{9}$ Horizonte A do solo, contendo o folhiço - substrato rico em matéria orgânica e micro-organismos do solo. 
ansiavam e mobilizavam-se para preservar os distintos ecossistemas existentes no morro, e, de outro lado, os "proprietários de terras" no morro, querendo explorá-las e loteá-las (a dita especulação imobiliária). Estes convictos de que "a existência de uma unidade de conservação ambiental dentro de uma grande zona urbana, como o PNMO em Porto Alegre, parece ser uma heresia do ponto de vista imobiliário" (OLIVEIRA, 2004, p. 15).

Assim, no final da década de 1970, contrariando o processo de pressão de empreiteiras e particulares sobre a Prefeitura para viabilizar loteamentos no morro, deu-se o início da "luta ecologista" no Morro do Osso - com a criação da Associação de Defesa do Ecossistema do Morro do Osso (ADEMO), contando na época com o apoio da Associação Gaúcha de Proteção ao Ambiente $(\text { AGAPAN })^{10}$ e diversos cidadãos atuantes, como professores, biólogos, jornalistas, artistas, vereadores, secretários municipais e moradores da região. Já em 1979 o primeiro Plano Diretor da Cidade de Porto Alegre designa o Morro do Osso como "área de preservação ecológica", ${ }^{11}$ e, em 1985, a Câmara Municipal considera o Morro do Osso como Reserva Ecológica da cidade e o movimento ambientalista lança a campanha "Parque Ecológico do Morro do Osso já” (OLIVEIRA, 2004).

No ano de 1987, a ADEMO encontrava-se desativada; deste modo, a empresa Solo Incorporações Ltda., aproveitando-se da situação, volta a articular junto à Prefeitura o seu projeto de loteamento no morro. Novamente houve mobilização ambientalista e comunitária para se contrapor ao loteamento do morro. Como resultado desse novo conflito de interesses [em 1987] surge, através da organização civil, a criação da Comissão Permanente de Defesa do Morro do Osso (CPDMO). Esta atuou contra projetos de loteamentos no morro, pressionando o poder público pela efetiva criação do parque; visto que, por mais que em 1979 e 1985 o poder público tenha categorizado o Morro do Osso como território de preservação, de fato esta [preservação] ainda não estava plenamente garantida. Sendo assim a CPDMO teve papel fundamental, na época, para "tensionar" e tornar o conflito socioambiental (entorno do destino do morro) cada vez mais visível ao cidadão porto-alegrense. A CPDMO foi transformada em ONG AMOSS - Associação de Defesa do Morro do Osso - em 2004. (OLIVEIRA, 2004).

Conforme afirmações contidas no plano de manejo do PNMO, foi a partir da década de 1990 que se consolidou um dos maiores "problemas" para a conservação efetiva e eficiente, ecologicamente falando, no Morro do Osso: foi "a expansão urbana, que praticamente cercou a área prevista para o parque, tornando-a insular" (SESTREN-BASTOS, 2006, p. 14), ou seja, uma ilha verde $^{12}$ no meio da urbe cinza. "Com a retirada de vegetação florestal para a construção de casas e condomínios fechados, sendo estes responsáveis, atualmente, pela maior derrubada de árvores, pois as construções ocupam, muitas vezes, mais de $90 \%$ da área de cada terreno." (SESTREN-BASTOS, 2006, p. 14). Mais recentemente, tal "ilhamento" agravou-se devido às construções de megaprédios em áreas de corredor ecológico do parque. Podemos citar, como exemplo, a construção de uma faculdade privada num terreno de áreas verdes na junção das avenidas Cavalhada e Eduardo Prado, que está sendo instalada num terreno localizado exatamente no local apontado pelo plano de manejo do PNMO como sendo o principal corredor ecológico do parque.

Em meados da década de 1990, foi criado um grupo técnico pela Coordenação do Ambiente Natural da SMAM para estudar a viabilidade da implementação de uma unidade de conservação na área. A formação desse grupo efetivou-se devido à necessidade de se estabelecer uma medida compensatória para um assentamento urbano no sopé do morro - junto à Avenida Cavalhada, chamado Loteamento Cavalhada, que, na época, abrigou as pessoas realocadas de áreas de risco. ${ }^{13} \mathrm{E}$ foi justamente

\footnotetext{
${ }^{10}$ A AGAPAN é uma das primeiras entidades de militância ecológica do Brasil e da América Latina e foi fundada por um grupo de naturistas em 27 de abril de 1971. Sua história se confunde com o surgimento do movimento ambientalista no país, principalmente por intermédio da figura de José Lutzenberger (ex-ministro do Meio Ambiente no governo Collor).

${ }^{11}$ Lei Complementar Municipal n ${ }^{\circ 3}$, de 21 de julho de 1979.

${ }^{12}$ Utiliza-se aqui o conceito de ilha para darmos vazão à noção de isolamento, ou seja, o fragmento florestal em questão tem conectibilidade (corredores ecológicos) com outras porções florestais dificultadas e interrompidas, assim restringindo o trânsito dos seres vivos e, consequentemente, diminuindo o fluxo gênico das espécies. Para saber mais sobre a noção de ilhamento, ver as teorias de "biogeografia de ilhas", "metapopulações" e "fragmentação de habitats".

${ }^{13}$ Antiga vila Cai-Cai, na orla do Lago Guaíba, local onde hoje se encontra a Fundação Iberê Camargo.
} 
a partir da medida compensatória do assentamento dessa comunidade que 27 hectares foram destinados à preservação. Consequentemente, a partir dessa área inicial, deu-se a criação do Parque Natural Morro do Osso, onde atualmente encontra-se o prédio da sede administrativa do parque (SESTREN-BASTOS, 2006).

O PNMO é uma UC de Proteção Integral (ou seja, de uso indireto) - na categoria de Parque Natural -, conforme o Sistema Nacional de Unidades de Conservação (SNUC - Lei Federal nº 9.985/2000). O PNMO foi criado pela Lei Complementar $n^{\circ} 334$, de 27 de dezembro de 1994, compreendendo uma área de 114 hectares, administrados em nível municipal pela Secretaria Municipal do Meio Ambiente (SMAM). O Plano Diretor de Diretrizes Urbanoambientais (PDDUA) ampliou essa área para 127 hectares no ano de 1999 (SESTREN-BASTOS, 2006). No entanto, há que se ressaltar que a Prefeitura de Porto Alegre possui, até o presente momento, propriedade sobre apenas 27 hectares; as demais áreas de posse (100 ha) a serem adquiridas pela Prefeitura estão em vagarosos trâmites de desapropriação, isso tendo em vista que os proprietários de terrenos correspondentes à área delimitada enquanto PNMO supervalorizam suas posses. Frisamos que a região é uma das mais nobres e valorizadas da cidade, portanto, torna-se demasiadamente oneroso à Prefeitura a compra de tais áreas.

No dia 14 de setembro de 2006, foi criado, por meio do Decreto $n^{\circ} 15.300$, o Conselho Consultivo do PNMO. Segundo o Decreto, o Conselho Consultivo "tem por objetivo contribuir para com a implantação e desenvolvimento da Unidade de Conservação" e é "composto por representantes de sociedade civil e de órgãos públicos”. Também em 2006 (26 de outubro) foi aprovado, pela Portaria n ${ }^{\circ}$ 268/06, o Plano de Manejo do PNMO. Até o início de 2004, a presença indígena no Morro do Osso era praticamente invisibilizada. Mostra disso pode ser percebida no trecho abaixo, no qual os autores descrevem os atores sociais que consideram relevantes no cenário cotidiano do PNMO e seu entorno:

Alguns personagens mantêm um contato diário com o PNMO, participando ativamente de sua rotina, contribuindo para que o mesmo cumpra suas funções. Neste grupo podem-se incluir os servidores do PNMO - sua administradora, os guarda-parques e demais funcioná- rios. Outros mantêm um contato menos freqüente com o Parque, mas participam indiretamente das questões mais importantes que digam respeito ao Morro do Osso. Neste grupo destacam-se a Comissão Permanente em Defesa do Morro do Osso (CPDMO) e o Conselho do Parque Natural Morro do Osso - ambos formados basicamente pelas mesmas pessoas. Incluem-se também a Diretora da Divisão de Administração de Parques (DAP) da Secretaria Municipal do Meio Ambiente (SMAM), à qual o PNMO está subordinado, e a Superintendência do Meio Ambiente (SUMAM) da SMAM. Outros participam ainda menos ativamente da rotina do Parque, realizando visitas esporádicas, com um caráter de aprendizado. Os principais representantes deste grupo são as escolas, os escoteiros e as Universidades, que realizam saídas de campo no local. [...] Um último grupo representa o outro lado interessado nas questões inerentes ao PNMO, os proprietários de terras localizadas dentro da área delimitada como Parque e de sua faixa de amortecimento. Esses apresentam interesses contrários à institucionalização do Parque Natural Morro do Osso, e se mostram quase todos favoráveis à especulação imobiliária. (OLIVEIRA; MISOCZKY, 2004, p. 7).

\section{Por outro lado:}

[...] no final do ano de 2003 - portanto, antes do estabelecimento dos Kaingang no Morro do Osso - o Núcleo de Antropologia das Sociedades Indígenas e Tradicionais (NIT) foi acionado pela direção do Parque Municipal do Morro do Osso devido a uma preocupação em tentar localizar o cemitério indígena ali referido. [...] Naquela ocasião, foi possível constatarmos que a direção e funcionários do parque sabiam da presença eventual de indígenas ali: fomos notificados pelos guarda-parques da presença relativamente constante de indígenas que por vezes foram avistados e afugentados dali por estarem em meio à mata "arrancando" os cipós e "destruindo" a vegetação. (SOUZA-PRADELLA; SALDANHA, 2008, p. 55).

Atualmente o morro é frequentado principalmente por moradores da região (Kaingang e não Kaingang), escolas, escoteiros e universidades. Muitos moradores locais utilizam as diversas trilhas do morro como "passo" - passagem de um lado a outro do morro e atalhos de menores distâncias. Ultimamente existem poucas 
pesquisas científicas sendo realizadas no PNMO. As atividades realizadas anualmente pela administração do PNMO são o Passeio Ciclístico, culminando com o Abraço ao Morro do Osso, e o Festival de Pandorgas. ${ }^{14}$

A insegurança também é um problema para a administração, indígenas, frequentadores e moradores do entorno do PNMO. Há relatos de assaltos e até mesmo estupros em áreas do PNMO, problemas que existem em diversos outros lugares, mas nem por isso cabe omiti-los. A própria sede administrativa já foi roubada diversas vezes, inclusive com a presença dos funcionários, que foram rendidos e amarrados durante a ação dos bandidos. Também cabe pontuar a presença de motoqueiros no interior do parque; para esses é uma diversão (esporte) andar de moto nas trilhas do morro, mas tal fato não é permitido e é visto pela administração como um sério problema, devido ao perigo que oferece aos pedestres e à erosão provocada nas trilhas pela ação de tração das rodas das motocicletas no solo, o que é agravado com o escoamento da água das chuvas. Outro fato que também é visto como um problema ambiental pela administração do PNMO são as práticas de cultos de religiões afro-brasileiras no interior e nas imediações do parque, devido ao fato de que em tais práticas religiosas realizam-se oferendas (vulgarmente denominadas de macumbas ou despachos), o que é visto (pela administração do PNMO) como lixo: uma poluição estético-sanitária na paisagem do parque. Além disso, registram-se pequenas infrações, como o acesso a áreas restritas, entrada de carros, trânsito de animais domésticos fora da guia de condução, dentre outras.

\section{O conflito da sobreposição: a institucionalização do PNMO e a "reterritorialização" Kaingang no Morro do Osso}

Embora o conflito socioambiental no Morro do Osso não se dê a partir da presença cotidiana Kaingang no morro - e sim já estava deflagrado anteriormente sob outras influências e perspectivas, como a especulação imobiliária das classes mais abastadas e também de moradias irregulares das classes menos favorecidas financeiramente sobre as encostas e baixadas do morro, entrando em choque direto com as perspectivas ambientalistas de proteger e conservar esse fragmento florestal de um crescimento urbano na região -, a entrada neste cenário confere uma configuração diferenciada no teor destas disputas.

Freitas (2005), referindo-se à entrada Kaingang no PNMO, diz que: "Esta primeira ocupação permanente do Morro do Osso efetivou-se após mais de dez anos de pesquisa e trânsito dos Kaingang nas florestas deste local." (FREITAS, 2005, p. 306). Já segundo Aquino (2009a), a constituição de uma nova aldeia no Morro do Osso:

Envolveu ao menos duas facetas da deambulação Kaingang. De um lado, o deslocamento, mü jé ha si ("vamos perto") e a conseqüente "transformação" do Morro do Osso em aldeia a partir de uma ruptura faccional na aldeia Lomba do Pinheiro. De outro lado, uma sobreposição desse deslocamento com um "outro" deslocamento, uma trajetória orientada por uma dimensão cosmológica, a saber, um mü jé ha si ("caminho dos antigos"). (2009a, p. 1-2).

Este último (mü jé ha si - lugar onde "os antigos passaram") deve-se às declarações Kaingang da existência de um vënh kej sí (cemitério indígena ancestral) no Morro do Osso, originário de tempos remotos de uma ga si (aldeia antiga ou "terra perdida") onde estão "sepultados nossos ancestrais", portanto uma afirmativa escatológica Kaingang (AQUINO, 2009a). Deste modo, SILVA et al. (2008) afirmam que

a Aldeia do Morro do Osso, portanto, possui para seus moradores Kaingang um valor inscrito na sua memória social e uma dimensão simbólica, relacionada às suas concepções cosmológicas, cujos contornos culturais e sociocosmológicos são imprescindíveis para a reconstrução e manutenção de suas singularidades. Trata-se de um local único, um território de memória, cosmológico e de sustentabilidade, onde é possível reproduzir seu modo de vida ancestral (p. 124).

${ }^{14}$ Pandorgas, também denominadas de pipas e/ou arraias em outras regiões do Brasil. 
Souza-Pradella (2008) refere-se à ambiência Kaingang no Morro do Osso, mais especificamente (a "Toca dos Índios", Tupë pën e o cemitério Kaingang) locais que "formam um conjunto de marcos de ambiência, ${ }^{15}$ reconhecidos pelos Kaingang através de suas muitas referências. É a partir deste feixe que os Kaingang acessam seu passado sistematizando neste presente.” (p. 11). "Estes marcos implicam a possibilidade de sua própria historicização na região de Porto Alegre, uma vez que suscitam em Francisco [liderança Kaingang] uma série de narrativas e lembranças sobre as viagens dos avós que desciam a serra para tratar com os brancos." (p. 9). Como vemos nos fragmentos abaixo:

E aqui eu descobri. O meu avô, o meu bisavô, ele já falava que aqui existia uma terra indígena, uma aldeia indígena no passado, que ele vinha. Quando ele vinha conversar com o governador, na época, naquela época eles vinham a pé e eles ficavam, era onde eles repousavam. O meu avô me dizia: nós temos uma área, uma terra indígena que é nossa, lá perto do gój kafó tu, ele dizia. Porque ele não sabia falar em português ele dizia, lá perto do gój kafó tu [...] Ele falava na nossa linguagem. [...] E esse gój kafó tu, ele quer dizer um rio muito grande. E esse rio nós podemos ver agora que é o Guaíba. Esse Guaíba, para aquelas bandas ele não tem mais fim, ele vai se emendar com o mar, ele vai embora. (Franscisco Arok̈̈, liderança da Aldeia Tupë pën).

Apesar da presença e desse conjunto de signos e sinais que justificam sua presença, há um movimento "antipresença indígena" no Morro do Osso. Essa mobilização de oposição à presença Kaingang é constituída pela própria Prefeitura Municipal de Porto Alegre principalmente nas figuras da SMAM e do PNMO - e por outras entidades como: Associação dos Moradores do $7^{\circ}$ Céu (AMSC), Associação dos Amigos do Morro do Osso (AMOSS), proprietários de terras, especulação imobiliária, mídia corporativa, ambientalistas e alguns acadêmicos e pesquisadores. Abaixo apresentamos trechos retirados de dois trabalhos acadêmicos que trazem elementos que demonstram a representação desse posicionamento "antipresença indígena" no morro, visto como um "problema" a ser resolvido:

Como se percebe, o processo de institucionalização do PNMO se mostra ainda muito incipiente. Um novo grande problema surgido neste ano [2004] fez com que novos grupos de interesse interferissem na institucionalização do PNMO. Nas primeiras semanas do mês de abril um grupo de índios caingangues invadiu a área do Morro do Osso, alegando que a área pertenceu a seus antepassados. O ponto irônico da situação é que os índios descobriram isso através da página da SMAM na internet, onde consta[m] os motivos pelos quais foi adotado o nome de PNMO. A SMAM alega que só existem lendas de que o morro abrigou um cemitério indígena, não havendo indícios concretos. Além disso, o cemitério seria de índios arachanes (guaranis), e não de caingangues. [...] Entre outros movimentos, se faz extremamente necessário que a Prefeitura compre ou negocie as demais áreas restantes do Parque, ainda em mãos de particulares, e garanta oficialmente a posse dessas áreas. Buscar o comprometimento da Câmara de Vereadores e da Prefeitura Municipal é importantíssimo, bem como impedir a interferência do poder legislativo estadual, que está sendo mobilizado pelos caingangues. Também novas formas de educação ambiental junto à população do entorno, garantindo sua participação no processo de institucionalização são imprescindíveis para que o parque se objetifique. Objetificando-se o Parque, a luta por sua sedimentação ficará um pouco mais fácil e menos utópica do que parece hoje. (OLIVEIRA; MISOCZKY, p. 10-11, grifos nossos).

Outro problema enfrentado é a ocupação indígena de um grupo de origem Kaigangue, onde existem oito famílias, totalizando trinta crianças, morando no morro desde 2004. Eles usam o cipó para artesanatos, que são retirados das árvores, deixando estas vulneráveis e com poucas chances de regeneração, já que a área do morro é considerada pequena para ocupação e exploração. O caso foi levado até a Fundação Nacional do Índio (FUNAI), que encaminhou um técnico para avaliar a questão e ainda nada foi decidido. Não foram encontrados vestígios arqueológicos de cemitério, tampouco

\footnotetext{
${ }^{15}$ Cf. Baudrillard (1993). E especificamente sobre a ambiência Kaingang e seus marcos de ambiência no Morro do Osso, ver: Souza-Pradella (2008) e Souza-Pradella e Saldanha (2008).
} 
de ocupação indígena nesta área, confirmando que a região não é de uso tradicional destes povos. $O$ plano de manejo prevê a desapropriação da área para que este problema seja solucionado. (ALARCON, 2007, p. 8 , grifos nossos).

Em abril de 2011, completaram-se sete anos que a comunidade Kaingang da Aldeia Tupë pën no Morro do Osso encontra-se estabelecida (ainda sem definição legal) em áreas adjacentes de uma antiga pedreira na "fronteira" entre o Parque e a rua Pe. Werner (bairro Tristeza/Sétimo Céu). O processo movido pela Prefeitura pela reintegração de posse encontra-se tramitando em terceira instância no Supremo Tribunal Federal e o Grupo Técnico nomeado pela Funai para a realização de estu$\operatorname{dos}^{16}$ - com a finalidade de caracterização da ocupação Kaingang em áreas do Morro do Osso - encontra-se em andamento (atualmente realizando estudos complementares ${ }^{17}$ ); assim, o território do Morro do Osso encontra-se em situação de litígio judicial.

Ao mesmo tempo, verificam-se impunemente algumas práticas de empreendimentos imobiliários da engenharia civil que derrubam o mato sem autorização do poder público. Tal constatação originou por parte da comunidade Kaingang do Morro do Osso, em abril de 2009, uma denúncia ${ }^{18}$ de desmatamento ao Ministério Público Federal que, posteriormente, foi repassada à competência do Ministério Público Estadual. Salienta-se que o citado desmatamento localiza-se no extremo oposto à localização da aldeia, local que no plano de manejo do PNMO está discriminado como área de corredor ecológico. Tal ação sustenta os discursos de preservação ambiental sempre manifestados pelas lideranças desta comunidade.

"A comida, a nossa comida: a própria natureza dava para nós, para os povos indígenas. Tanto nós Kaingang, como os Guarani, os Xavante, como todos nós indígenas daqui da terra brasileira, quem dava sustento, comida, alimento para nós e para nossos filhos era a própria mata, a própria natureza, então nós preservávamos ela. Hoje não tenho mais como preservar, hoje eu luto, eu tento, eu falo, conto história para os jovens, eu choro, eu tento preservar uma ponta de mato que ainda resta para dar sustento aos meus filhos." (Franscisco Arokÿ, liderança da aldeia Tupë pën).

Como também constatado pelo diagnóstico ${ }^{19}$ realizado pela Fundação de Educação Social e Comunitária (FASC) em parceria com o Laboratório de Observações Sociais (LABORS/UFRGS) realizado em 2007-2008:

Na percepção dos interlocutores kaingang da Aldeia Morro do Osso, sua presença atual na área contígua ao Parque Natural do Morro do Osso vem produzindo efeitos positivos no que diz respeito à proteção do meio ambiente. Segundo seus relatos, várias espécies de pássaros que antes não eram observadas agora são vistas com freqüência. Da mesma forma, dizem ter notado o aumento do mato, incluindo árvores, plantas medicinais e fibras vegetais, e um crescente circular de animais, inclusive bugios, antes não visualizados. De acordo com seus depoimentos, consideram-se os protetores da natureza do Morro do Osso, mencionando sua relação anímica com os elementos deste domínio cosmológico, em especial com as fontes de água e com as árvores. Igualmente, pensam que sua retomada da antiga aldeia e presença na área do Parque Natural do Morro do Osso foi fundamental para sustar empreendimentos imobiliários que estavam se desencadeando quando da sua chegada ao Morro em 2004. (SILVA et al., 2008, p. 124-125).

Tais fatos mostram alguns aspectos e formas pelas quais são deflagradas outras dinâmicas de argumentação e de busca de alianças por parte dos envolvidos. Nesse caso, o discurso preservacionista soma-se ao modo de ser Kaingang, mostrando que, apesar de em determinados

\footnotetext{
${ }^{16}$ Projeto 914/BRA/4008 (FUNAI/UNESCO). Edital 022/2009 - laudo antropológico e Edital 023/2009 - laudo ambiental.

${ }^{17}$ Estudos de natureza etno-histórica, antropológica e ambiental, conforme as Portarias da FUNAI n ${ }^{\circ} 531$ (de 14/4/2011) e n ${ }^{\circ} 581$ (de 15/04/2011).

${ }^{18}$ Inquérito Civil Público n ${ }^{\circ}$ 00833.00056/2009 está em andamento - atualmente a Promotoria de Defesa do Meio Ambiente aguarda diligência (ofício de reiteração) da SMAM.

19 Visando visibilizar a realidade de alguns segmentos historicamente marginalizados da sociedade brasileira. A referida pesquisa teve por objetivo principal "colher informações sobre as populações em risco social no município de Porto Alegre". Os dados referentes às populações indígenas neste município encontram-se publicados em Silva et al. (2008)
} 
momentos os discursos apresentarem-se divergentes, em outros convergem. Expõem também outros atores sociais e interesses que permeiam o conflito, desvelando a complexidade da situação a qual fazemos um recorte com fins analíticos.

\section{Considerações finais}

Os dados etnográficos e de fonte secundária configuram uma situação de conflitos em que são expostas duas concepções distintas de mundo, correspondentes a duas matrizes cognitivas diferenciadas. Estes, a partir do acionamento de diferentes argumentos na estrutura interna que os concebe, materializam-se em territorialidades diferenciadas. O conflito se configura justamente na situação da busca de legitimidade de cada uma dessas lógicas de argumentação.

O fato da alteridade Kaingang em Porto Alegre com sua complexidade existencial - ter de interagir com um poder público difuso, permeado pelas contradições inerentes à estrutura kafkaniana de diferentes instâncias, departamentos e repartições técnico-burocráticas segmentadas, tem aumentado ainda mais as dificuldades de seus integrantes fazerem valer seus direitos constitucionais. Apesar de os Kaingang terem se apropriado e se encontrarem hoje inseridos em diversas políticas públicas, tais impeditivos (na maioria das vezes, não explícitos e não ditos) de acesso a direitos legais assegurados na Constituição Federal terminam por comprometer sua autonomia, segurança alimentar, bem como seus modos de vida e a própria reprodução sociocultural de suas comunidades.

Como visto ao longo deste artigo, paralelamente a este fenômeno, a atuação de atores sociais com interesses por vezes muito distintos (como secretarias municipais, ONGs ambientalistas, acadêmicos e empresas ligadas à construção civil e/ou especulação imobiliária) pode estar, paradoxalmente, contribuindo para a marginalização dos grupos Kaingang que vivem em Porto Alegre e arredores. Tal como outros procedimentos neocolonialistas, a seu modo, as ações desses atores com pontos de vista conflitantes vêm somar-se a outras práticas já seculares de marginalização e exclusão social de povos indígenas, sendo o resultado mais evidente - como fica claro no caso dos conflitos no (e pelo) Morro do Osso - a ampla desterritorialização forçada que o povo Kaingang vem sofrendo.

A esta perda de seus territórios é que seus integrantes vêm resistindo, com estratégias de contraposição, reafirmando uma iniciativa sustentada por diversas outras etnias indígenas: a audaciosa teimosia (no melhor sentido da palavra) de se negarem a ser "brancos". Para tanto, se reinventam permanentemente enquanto grupo étnico singular, adaptam seus sistemas sociocosmológicos e suas práticas culturais à realidade concreta vivida junto aos não Kaingang e, obviamente, emergem como protagonistas e se impõem enquanto sujeitos políticos nas diversas arenas públicas e instâncias decisórias.

Todas essas situações podem tanto ser lidas a partir de uma crítica à dinâmica da sociedade ocidental civilizadora eurorreferenciada (na direção de um etnocídio dos diferentes) como podem se configurar como sinais de um processo de crise dessa mesma sociedade, que, diante da constatação de inúmeros desencaixes da modernidade, busca no outro uma saída para sua crise. Acompanhar e debater situações de conflitos dessa natureza podem trazer elementos para enriquecer esse debate, ainda muito longe de um desfecho.

No entanto, até o presente momento, percebemos um quadro "adialógico", ou seja, a disputa se dá sem diálogos entre as "partes concorrentes", não sendo visualizado um "espaço-meio" de conciliamento das distintas territorialidades; muito disso deve-se ao fato da "judicialização" do litígio em questão, o que acarreta a ausência de outras arenas públicas que coloquem as partes em debate para a resolução do conflito. Assim, configura-se um espaço de diálogo exclusivamente através da frieza dos tribunais, onde as partes enfrentam-se a fim de sobreporem seus argumentos ao dos "concorrentes", na intenção de firmar apenas seu ponto de vista em detrimento do outro e "vencer" a disputa.

Portanto, pensar em um consenso, em um trabalho conjunto entre as duas territorialidades sobrepostas, como, por exemplo, uma gestão compartilhada ou uma desafetação na categoria da UC - permitindo e reconhecendo a presença indígena -, na qual visualiza-se um território em mosaico com a demarcação de uma TI em parte do morro e, em outra parte, permanecendo uma UC. Entretanto, na presente conjuntura, esta possibili- 
dade está fora de cogitação, tendo em vista as diferentes perspectivas das partes envolvidas.

Deste modo, o futuro do Morro do Osso é incerto e, se mantido esse "percurso adialógico", projetamos um desfecho de "ganhadores e perdedores", no qual, de um lado, estão os Kaingang da Aldeia Tupë pën e seus aliados ("lutando" pela demarcação de uma TI no morro) e, do outro, a Prefeitura Municipal de Porto Alegre, na figura da SMAM, (defendendo a manutenção da institucionalização do PNMO). Neste cenário, poderíamos presumir

\section{Referências}

ALARCON, L. de. Unidades de Conservação Ambiental no $R S$ : panorama atual, estudo de caso: Parque Natural Morro do Osso, Porto Alegre. Monografia (Licenciatura em Biologia) - Universidade do Vale do Rio dos Sinos. São Leopoldo-RS, 2007.

AQUINO, A. M. Ën Ga Vyg Ën Tóg ("Nós Conquistamos Nossa Terra"): os Kaingang no litoral do Rio Grande do Sul. Dissertação (Mestrado em Antropologia) - UnB. Brasília, 2008.

. Ritual, alteridade e territorialidade Kaingang na fundação de aldeia no Morro do Osso. In: REUNIÃO DE ANTROPOLOGIA DO MERCOSUL. DIVERSIDAD Y PODER EN AMÉRICA LATINA, 8., Buenos Aires. Anais... Buenos Aires, 2009a.

. Mü jé ha ("Vamos"): a fundação de aldeias Kaingang no litoral do Rio Grande do Sul. Tellus, Campo Grande-MS, ano 9 , n. 17, p. 111-136, 2009 b.

BAUDRILLARD, J. O sistema dos objetos. São Paulo: Perspectiva, 1993.

BRACK, P. et al. Árvores e arbustos na vegetação natural de Porto Alegre, Rio Grande do Sul, Brasil. Iheringia, Série Botânica, Porto Alegre, v. 51, n. 2, p. 139-166, 1998.

CALDRE E FIÃO, J. A. Ibicui retã. Boletim Municipal, Porto Alegre, v. 6, n. 15, p. 418-424, 1943.

CUNHA, M. C. da. Cultura com aspas e outros ensaios. São Paulo: Cosac Naïfy, 2009.

FREITAS, A. E. de C. Mrûr Jykre - a cultura do cipó: territorialidades Kaingang na margem leste do Guaíba, Porto Alegre, Rio Grande do Sul, Brasil. Tese (Doutorado em Antropologia) - UFRGS. Porto Alegre, 2005. apenas um "vencedor" devido à improvável conciliação entre estas distintas territorialidades no Morro do Osso. $\mathrm{Na}$ atual conjuntura fica a questão: quem será o vencedor, Parque ou Aldeia? Mas, já no caso de uma mudança no rumo das negociações, onde seria necessária a criação de um espaço dialógico entre as partes envolvidas, poderíamos vislumbrar uma conciliação entre as distintas territorialidades e, quiçá, a possibilidade de um convívio mútuo e formalizado entre a Unidade de Conservação e a Aldeia Kaingang em áreas do Morro do Osso.
. Mrũr Jykre - a cultura do cipó: territorialidades Kaingang na Bacia do Lago Guaíba, Porto Alegre, Rio Grande do Sul, Brasil. In: KUBO, R. R. et al. (Org.). Atualidades em Etnobiologia e Etnoecologia. v. 3. Recife: Nuppea/SBEE, 2006.

. Nossos contemporâneos indígenas. In: FAGUNDES, L. F.; FREITAS, A. E. (Org.). Povos indigenas na bacia hidrográfica do lago Guaiba. Prefeitura de Porto Alegre, Secretaria Municipal de Direitos Humanos e Segurança Urbana, Núcleo de Políticas Públicas para os Povos Indígenas. Porto Alegre, 2008.

HASENACK, H. et al. (Coord.). Diagnóstico ambiental de Porto Alegre: geologia, solos, drenagem, vegetação/ocupação e paisagem. Porto Alegre: Secretaria Municipal do Meio Ambiente, 2008.

MENEGAT, R. (Coord.). Atlas Ambiental de Porto Alegre. 2. ed. Porto Alegre: Editora da Universidade, 1999.

MIRAPALHETE, S. R. (Org.). Flora e fauna do Parque Natural Morro do Osso. Porto Alegre: Secretaria Municipal do Meio Ambiente, 2001.

OLIVEIRA, R. P. de. Desafios para a institucionalização de uma Unidade de Conservação junto a um entorno urbano. Monografia (Graduação em Administração de Empresas) UFRGS. Porto Alegre, 2004.

; MISOCZKY, M. C. O processo de institucionalização do Parque Natural Morro do Osso. In: ENCONTRO DE ADMINISTRAÇÃO PÚBLICA E GOVERNANÇA, 1., Rio de Janeiro. Anais... Rio de Janeiro: ANPAD, 2004. 1 CD-ROM.

ROSA, R. R. G. da. "Os kujà são diferentes": um estudo etnológico do complexo xamânico dos Kaingang da terra indígena Votouro. Tese (Doutorado em Antropologia) - UFRGS. Porto Alegre, 2005. 
FUHR, G.; GERHARDT, C. H.; KUBO, R. R. Entre Aldeia Kaingang ou Parque Natural: o processo de configuração...

SALDANHA, J. R. P. “Eu não sou pedra para sempre”: cosmopolítica e espaço Kaingang no Sul do Brasil Meridional. Dissertação (Mestrado em Antropologia) - UFRGS. Porto Alegre, 2009a.

Constituição da aldeia Kaingangue do Morro do Osso. Cosmopolítica e fronteiras étnicas e (ou) de alteridade nas retomadas territoriais indígenas por mundos sociais em encontro. In: KERN, A. et al. (Org.). Povos indigenas - Coleção História Geral do Rio Grande do Sul. v. 5. Passo Fundo: Livraria e Editora Méritos Ltda., 2009b.

SCHMITZ, P. I. Povos indígenas associados à Floresta com Araucária. In: FONSECA, C. R. et al. (Eds.). Floresta com Araucária: ecologia, conservação e desenvolvimento sustentável. Ribeirão Preto: Holos Editora, 2009.

SESTREN-BASTOS, M. C. (Coord.). Plano de manejo participativo do Parque Natural Morro do Osso. Porto Alegre: Secretaria Municipal do Meio Ambiente, 2006. Disponível em: <http://proweb.procempa.com.br/pmpa/prefpoa/smam/ usu_doc/plano_de_manejo_morro_do_osso_com_anexos. pdf $>$. Acesso em: abril de 2010 .

SILVA, S. B. da. Etnoarqueologia dos grafismos Kaingang: um modelo para a compreensão das sociedades Proto-Jê meridionais. Tese (Doutorado em Antropologia) - USP. São Paulo, 2001.
. Dualismo e cosmologia Kaingang: o xamã e o domínio da floresta. Horizontes Antropológicos. Porto Alegre: PPGAS/ UFRGS, n. 18, p. 189-209, 2002.

. Nomes e performances: fabricando corpos Kaingang. In: SILVEIRA, E. da; OLIVEIRA, L. D. de (Org.). Etnoconhecimento e saúde dos povos indígenas do Rio Grande do Sul. Canoas: Ed. Ulbra, 2005.

. Sociocosmologias indígenas no espaço metropolitano de Porto Alegre. In: GEHLEN, I.; SILVA, M. B.; SANTOS, S. R. dos (Org.). Diversidade e proteção social: estudos quanti-qualitativos das populações de Porto Alegre. Porto Alegre: Century, 2008.

et al. Coletivos indígenas em Porto Alegre e regiões limítrofes. In: GEHLEN, I.; SILVA, M. B.; SANTOS, S. R. dos (Org). Diversidade e proteção social: estudos quanti-qualitativos das populações de Porto Alegre. Porto Alegre: Century, 2008.

SOUZA-PRADELLA, L. G. de. Tempo, espaço e referência: marcos de ambiência Kaingang no Morro do Osso. In: REUNIÃO BRASILEIRA DE ANTROPOLOGIA, 26., Porto Seguro. GT 34. Anais... Porto Seguro-BA, 2008.

; SALDANHA, J. R. P. A presença Kaingang no Morro do Osso entre diferentes perspectivas sociodiscursivas. Espaço Ameríndio, Porto Alegre, v. 2, n. 2, p. 52-82, 2008.

WIESEMANN, U. Dicionário Bilíngue Kaingang - Português. Curitiba: Editora Evangélica Esperança. 2002.

Recebido em 30 de abril de 2012.

Aceito em 19 de junho de 2012. Publicado em dezembro de 2012. 